\title{
Abciximab: a reappraisal of its use in coronary care
}

\author{
Marco Valgimigli \\ Gianluca Campo \\ Matteo Tebaldi \\ Roberto Carletti \\ Chiara Arcozzi \\ Roberto Ferrari \\ Gianfranco Percoco \\ Cardiovascular Institute, Azienda \\ Ospedaliera Universitaria S. Anna, \\ Ferrara, Italy and Cardiovascular \\ Research Centre, Salvatore Maugeri \\ Foundation, IRCCS Gussago (BS), Italy
}

\begin{abstract}
Platelet reactivity plays a pivotal role in the pathogenesis of ischemic adverse events during and after acute coronary syndromes (ACS), and percutaneous coronary intervention (PCI). Glycoprotein (GP) IIb/IIIa inhibitors are the strongest antiplatelet agents currently available on the market and three different compounds, namely abciximab, tirofiban, and eptifibatide, have been approved for clinical use. Abciximab has been investigated in the clinical field far more extensively than the other GPIIb/IIIa inhibitors. Abciximab is an anti-integrin Fab fragment of a human - mouse chimeric monoclonal antibody with high affinity and a slow dissociation rate from the GP IIb/IIIa platelet receptor. Abciximab, given shortly before the coronary intervention, is superior to placebo in reducing the acute risk of ischemic complications (EPIC, EPISTENT, EPILOG trials); moreover, in the ISAR-REACT 2 study abciximab has been shown to reduce the risk of adverse events in patients with non ST-segment elevation ACS who are undergoing PCI even after optimal pre-treatment with $600 \mathrm{mg}$ of clopidogrel. Finally, abciximab has been also used in abciximab-coated stent, with only bolus administration regimen and for direct intracoronary use with promising results that may extend and/or modify its current use in clinical practice in future.
\end{abstract}

Keywords: abciximab, percutaneous coronary intervention, myocardial infarction

Platelet reactivity plays a pivotal role in the pathogenesis of ischemic cardiovascular disorders (Kabbani et al 2001).

Both platelet activation and aggregation have been shown to be heightened in the setting of acute coronary syndromes (ACS) and current evidence supports the concept that spontaneous (Kabbani et al 2003) or drug-modulated (Matetzky et al 2004) propensity to platelet-clot formation is a strong and independent predictor of clinical outcome. Blocking platelet aggregation with various agents acting on different molecular pathways has been consistently demonstrated to be of unequivocal benefit in broad population of patients. Among the proposed pharmacological targets for antiplatelet therapy, the glycoprotein (GP) IIb/IIIa receptor continues to be among the most promising (Topol et al 1999). GPIIb/IIIa, the $\alpha \mathrm{IIB} / 33$ integrin, is a plateletspecific adhesion receptor with broad specificity for a number of ligands, most notably fibrinogen, von Willebrand factor (vWF), and prothrombin. $\alpha \mathrm{IIB} / 33$ integrin is the most abundant platelet membrane GP. GPIIb/IIIa mediates the formation of platelet aggregates via vWF and soluble fibrinogen. Platelet stimulation by soluble agonists (thrombin, adenosine diphoshate, and thromboxane A2) causes conformational changes of the receptor with subsequent transformation from a low- into a high-affinity state, allowing for ligand (circulating fibrinogen or vWF) binding. This conformational change of GPIIb/IIIa is not due to any direct action of the agonists on the receptor but results directly from receptor-mediated stimulation of intracellular signalling pathways that enhance ligand-affinity of GP IIb/IIIa. All GP IIb/IIIa antagonists react with the resting and active forms of $\alpha \mathrm{IIB} / \beta 3$ integrin and therefore all agents bind to non-stimulated and stimulated platelets, although with different affinities towards the 
receptor and in different binding sites (Schror et al 2003). The GPIIb/IIIa inhibitors are a class of agents blocking the binding of fibrinogen to activated GPIIb/IIIa, thereby inhibiting platelet-platelet interaction and thrombus formation. GPIIb/IIIa inhibitors have been shown to reduce secondary complications following percutaneous coronary intervention (PCI). Three GPIIb/IIIa inhibitors, abciximab, tirofiban, and eptifibatide, have been approved for clinical use in the United States and other countries (Table 1). They are given by intravenous administration whereas development of oral GP $2 b / 3 a$ inhibitors has been discontinued due to negative or even paradoxical findings in clinical trials.

This paper will focus on abciximab which provided robust, consistent, and significant reduction in death or myocardial infarction (MI) in several PCI trials.

\section{Pharmacodynamics and pharmacokinetics of abciximab}

Abciximab is an anti-integrin Fab fragment of a human - mouse chimeric monoclonal antibody with high affinity and a slow dissociation rate from the GPIIb/IIIa platelet receptor (Mager et al 2003; Schror et al 2003; Gowda et al 2004; Silva et al 2004; Atwater et al 2005). It has a short plasma half-life of 10-30 minutes, but a long biologic half-life due to its strong affinity to the GPIIb/IIIa receptor (67\% bound to the receptor). It remains bound in circulation for up to 15 days with minimal residual activity. Its receptor occupancy is 30\% at 8 days and $10 \%$ at 15 days. Despite prolonged receptor occupancy, platelet function returns to baseline 12-36 hours after therapy cessation mainly due to rapid platelet turnover (Mager et al 2003; Schror et al 2003; Gowda et al 2004; Silva et al 2004; Atwater et al 2005). Abciximab-coated platelets can be detected in the circulation for at least 2 weeks after treatment. Complete receptor blockade is obtained at approximately $5 \mu \mathrm{g} / \mathrm{mL}(100 \mathrm{nM})$. The binding site of abciximab is located at the $\beta$-chain of the $\mathrm{GPIIb} / \mathrm{III}$ receptor and is different from the binding site for the low-molecular-weight inhibitors eptifibatide and tirofiban (Mager et al 2003; Schror et al 2003; Silva et al 2004; Gowda et al 2004; Atwater et al 2005). The advantage of low plasma concentrations and the high receptor affinity allows reversibility of significant bleeding time with platelet transfusions. Mechanistically, the large antibody fragment (molecular weight about $50 \mathrm{kD}$ ) causes a steric hindrance of access of ligands to their binding pocket. This also explains its almost equimolar potency $(k D: 7 \mathrm{nM})$ for inhibition of the other $\beta 3$ integrin av/ $/ 33$, the vitronectin receptor at the surface of vascular cells, ie, the endothelium and vascular smooth muscle. At lower affinity $(k D$ : $160 \mathrm{nM}$ ), abciximab also interacts with the activated MAC-1 receptor on leukocytes (Mager et al 2003; Schror et al 2003; Gowda et al 2004; Silva et al 2004; Atwater et al 2005). These additional interactions with other integrins are not generally shared by other two low-molecular-weight antagonists. The clinical relevance of occupancy of non-GP IIb/IIIa receptors by abciximab has not been established. Abciximab has been shown to elicit an antibody response, particularly after readministration, most likely because of its large size and murine origin. On repeat dosing, this antigenicity of abciximab may increase the risk of thrombocytopenia (Aster 2005).

\section{Principal clinical studies using abciximab}

Given shortly before the PCI, abciximab is superior to placebo in reducing the acute risk of ischemic complications (the Evaluation of 7E3 for the Prevention of Ischemic Complications - EPIC - study [The EPIC Investigators 1994]; the Evaluation in Percutaneous Transcateter Coronary Angioplasty to Improve Long-term Outcome with Abciximab GP IIb/IIIa blockade - EPILOG - study [The EPILOG Investigators 1997]; the Evaluation of Platelet IIb/IIIa Inhibitor for Stenting-EPISTENT - study [The EPISTENT Investigators 1998], Table 2). Two studies, CAPTURE (The CAPTURE Investigators 1997) (the Chimeric 7E3 Antiplatelet in Unstable Angina Refractory to Standard Treatment study) and GUSTO IV-ACS (The GUSTO IV-ACS Investigators 2001) (the Global Utilization of Streptokinase and Tissue Plasminogen Activator for Occluded Coronary Arteries study) have evaluated the efficacy and safety of abciximab in the context of different management strategies for patients with non ST-segment elevation ACS (NSTEACS). In the CAPTURE (The CAPTURE Investigators 1997) study, 1265 patients who were admitted with unstable angina and who continued to have refractory ischemia underwent cardiac catheterization. Patients who were deemed good candidates for PCI were randomized into abciximab therapy for 18-24 hours before angioplasty and 1 hour after, or placebo treatment with coronary angioplasty. The primary composite end point at 30 days of death, MI, or urgent repeat intervention for recurrent ischemia was significantly less in patients who received abciximab (11.3\% abciximab vs $15.9 \%$ placebo; $\mathrm{p}=0.012$ ). The majority of benefit with abciximab was derived with reduction of peri-procedural MI (2.6\% abciximab vs 5.5\% placebo; $\mathrm{p}=0.009$ ), and a reduction in MI prior to intervention was also observed $(0.6 \%$ abciximab vs $2.1 \%$ placebo; $\mathrm{p}=0.0029)$. However, this favorable effect was lost at 6 months in the whole cohort of patients. It should be emphasized that greater benefit from platelet GPIIb/IIIa 
Table I Pharmacological data of principal GPIlb/llla inhibitors

\begin{tabular}{|c|c|c|c|}
\hline Parameter & Abciximab & Tirofiban & Eptifibatide \\
\hline Molecular weight $(\mathrm{Da})$ & $\sim 50000$ & $\sim 490$ & $\sim 800$ \\
\hline \multicolumn{4}{|l|}{ Receptor selectivity } \\
\hline GPIlb/IIla & High & High & High \\
\hline MAC-I & High & No & No \\
\hline Molecular mechanism & $\begin{array}{l}\text { Monoclonal antibody with high affinity } \\
\text { for GPIIb/IIla receptor }\end{array}$ & Competitive inhibitor & Competitive inhibitor \\
\hline Clearance & Platelet binding & Renal $(60 \%)+$ biliar (40\%) & Renal (90\%) \\
\hline \multicolumn{4}{|l|}{ Half-life (h) } \\
\hline plasma & 0.5 & 2 & 3 \\
\hline platelet & 4 & No & No \\
\hline Dissociation constant (nmol/L) & $\sim 5$ & $\sim 15$ & $\sim 120$ \\
\hline Antigenicity & Possible & No & No \\
\hline Reversibility of effect (h) & $72-96$ & 4 & $4-6$ \\
\hline
\end{tabular}

inhibitor therapy is mainly seen in NSTEACS patients who present with elevated baseline cTnT levels. Indeed, in this subset of patients the rates of death or MI at 6 months were profoundly reduced in the abciximab-treated cohorts even at 6 months (9.5\% abciximab vs $23.9 \%$ placebo; $\mathrm{p}=0.002)$.

The GUSTO IV-ACS (The GUSTO IV-ACS Investigators 2001) trial showed no significant benefit to abciximab in the medical management of NSTEACS. In the GUSTO IV-ACS (The GUSTO IV-ACS Investigators 2001), PCI was discouraged by the protocol and ultimately it was performed only in $1.6 \%$ of patients within 48 hours and in $19 \%$ within 30 days. Abciximab was associated with a trend towards higher early mortality (at 48 hours) than in the placebo arm. There was also a lack of any therapeutic benefit at 30 days. Thus, the American College of Cardiology (ACC)/American Heart Association (AHA) guidelines (Braunwald et al 2002) give a class III recommendation (either not effective or potentially harmful) for the addition of abciximab to standard antithrombotic therapy in patients in whom PCI is not planned. The negative results of the GUSTO IV-ACS trial may be explained by the lack of access to timely revascularization which is in keeping with the results of several other trials based on the use of GPIIb/IIIa inhibitors. All these landmark investigations were conducted in the pre-clopidogrel era. Thus, patients were randomized to abciximab vs placebo on a background of aspirin alone as antiplatelet agent.

To assess the hypothesis that abciximab may be a useful therapy in patients with NSTEACS undergoing PCI, even after pretreatment with a $600 \mathrm{mg}$ loading dose of clopidogrel, the ISAR-REACT 2 (Kastrati et al 2006) (the Intracoronary Stenting and Antithrombotic Regimen: Rapid Early Action for Coronary Treatment study) has been designed. Patients with an episode of angina (with an accelerating pattern, or prolonged, or recurrent episodes at rest, or with minimal effort) within the preceding 48 hours, accompanied by an elevated troponin level or a new finding of ST-segment depression or new or presumed new bundle-branch block undergoing PCI were enrolled, treated with $500 \mathrm{mg}$ of oral or intravenous aspirin plus $600 \mathrm{mg}$ clopidogrel, and randomized to abciximab or placebo. As result, a $25 \%$ reduction of the risk of recurrent ischemic events among patients assigned to abciximab was observed. Notably, the gradient in favor of abciximab was seen for all components of the primary end point (death, MI, and target vessel revascularization), although none reached statistical significance when considered individually. The adverse event rate observed in patients without an elevated troponin level was similar to that seen previously in the first ISAR-REACT trial (Kastrati et al 2004) (Table 2). In contrast, among patients with an elevated troponin level, the risk of recurrent ischemic events was considerably higher than that in those without elevated troponin levels and was reduced by $29 \%$ by abciximab.

When taken together current evidence suggests that the benefit of abciximab over placebo is proportional to the risk status of the patients. This notion should be kept in mind when interpretating the apparently negative results observed with abciximab in the ISAR-REACT study (Kastrati et al 2004).

Several trials have been conducted to test the role of abciximab in the setting of ST-segment elevation MI (STEMI). Recently, a meta-analysis has been published reporting 3-years follow-up data of 1101 patients presenting for primary PCI and stenting of STEMI randomized to abciximab or placebo (Montalescot et al 2007). This analysis included data from ADMIRAL (Montalescot et al 2001) (the Abciximab before Direct Angioplasty and Stenting in Myocardial Infarction regarding Acute and Long-term Follow-up study), ISAR-2 (Neumann et al 2000), and ACE (Antoniucci et al 2003) (the Abciximab and Carbostent Evaluation study) trials. 
Table 2 Abciximab use in clinical trials

\begin{tabular}{|c|c|c|c|}
\hline Trials & Population study & Design & Key information \\
\hline EPIC & $\begin{array}{l}2099 \text { pts scheduled to high risk } \\
\mathrm{PCl}\end{array}$ & $\begin{array}{l}\text { Placebo vs only bolus abciximab vs } \\
\text { bolus }+ \text { infusion abciximab }\end{array}$ & $\begin{array}{l}\text { Abciximab bolus + infusion } \\
\text { resulted in a } 35 \% \text { reduction in the } \\
\text { rate of the primary endpoint }\end{array}$ \\
\hline EPISTENT & $\begin{array}{l}2399 \text { pts receiving elective or } \\
\text { urgent } \mathrm{PCl}\end{array}$ & $\begin{array}{l}\text { Stent and placebo vs stent and } \\
\text { abciximab vs POBA and abciximab }\end{array}$ & $\begin{array}{l}\text { Abciximab and stent implantation } \\
\text { confer complementary long-term } \\
\text { clinical benefits }\end{array}$ \\
\hline EPILOG & $\begin{array}{l}2792 \text { pts receiving elective or } \\
\text { urgent } \mathrm{PCl}\end{array}$ & $\begin{array}{l}\text { Heparin vs abciximab + heparin vs } \\
\text { abciximab + low-dose heparin }\end{array}$ & $\begin{array}{l}\text { Reduction of acute ischemic com- } \\
\text { plications, without increasing the } \\
\text { risk of hemorrhage }\end{array}$ \\
\hline CAPTURE & 1050 pts with refractory UA & $\begin{array}{l}\text { Abciximab vs placebo. } \mathrm{PCl} \text { was } \\
\text { scheduled I8-24 h after medica- } \\
\text { tion }\end{array}$ & $\begin{array}{l}\text { Abciximab substantially reduces } \\
\text { the rate of } \mathrm{MI} \text {, before, during, and } \\
\text { after } \mathrm{PCl}\end{array}$ \\
\hline GUSTO IV-ACS & 7800 patients with ACS & $\begin{array}{l}\text { Placebo (heparin) vs abciximab } \\
\text { bolus }+ \text { infusion for } 24 \mathrm{~h} \text { vs abcix- } \\
\text { imab bolus }+ \text { infusion for } 48 \mathrm{~h}\end{array}$ & $\begin{array}{l}\text { No difference in } 30 \text {-day death or } \\
\text { Ml in main cohort and diabetic } \\
\text { subgroup analysis fails to reach } \\
\text { statistical significance }\end{array}$ \\
\hline TARGET & 5308 patients scheduled to $\mathrm{PCl}$ & $\begin{array}{l}\text { Tirofiban (RESTORE regime) vs } \\
\text { abciximab }\end{array}$ & $\begin{array}{l}\text { Lower incidence of death, re-MI, } \\
\text { and TVR in the abciximab group }\end{array}$ \\
\hline ISAR-REACT & Pts low risk undergoing $\mathrm{PCl}$ & $\begin{array}{l}600 \mathrm{mg} \text { clopidogrel vs } 600 \mathrm{mg} \\
\text { clopidogrel + abciximab }\end{array}$ & $\begin{array}{l}\text { Abciximab offered no clinically } \\
\text { measurable benefit at } 30 \text { days }\end{array}$ \\
\hline ISAR-REACT 2 & 2022 pts with ACS undergoing $\mathrm{PCl}$ & $\begin{array}{l}600 \mathrm{mg} \text { clopidogrel vs } 600 \mathrm{mg} \\
\text { clopidogrel + abciximab }\end{array}$ & $\begin{array}{l}\text { Reduction of the risk of adverse } \\
\text { events in patients with non-STseg- } \\
\text { ment elevation ACS }\end{array}$ \\
\hline
\end{tabular}

Abbreviations: ACS, acute coronary syndrome; $\mathrm{MI}$, myocardial infarction; $\mathrm{PCl}$, percutaneous coronary intervention; $\mathrm{POBA}$, percutaneous only ballon angioplasty; pts, patients; TVR, target vessel revascularization; UA, unstable angina.

The primary endpoint of death or re-infarction was significantly reduced from an estimated cumulative hazard rate of $19.0 \%$ with placebo to $12.9 \%$ with abciximab. The mortality rate was reduced from an estimated cumulative hazard rate of $14.3 \%$ in the placebo arm to $10.9 \%$ in the abciximab arm. Major bleedings were 2.5 and $2 \%$ with and without abciximab, respectively. In the control arm, both the death or MI cumulative hazard rate (54 vs $13.5 \%$ ) and mortality rate (39.7 vs $10.1 \%$ ) were 4 -fold higher in diabetics than non-diabetics. Abciximab provided a significant benefit on the primary endpoint for diabetics. A meta-regression analysis of randomized trials with abciximab in the primary PCI setting confirmed and expanded this observation (De Luca et al 2006).

\section{Principal clinical studies comparing abciximab to others GP IIb/IIla inhibitors \\ Abciximab vs tirofiban}

In the TARGET trial (Topol et al 2001) (the do Tirofiban and Abciximab Give Similar Efficacy Outcomes study), 5308 patients scheduled to urgent or elective PCI were enrolled and randomized to tirofiban (bolus $10 \mu \mathrm{g} / \mathrm{kg}$ and infusion of
$0.15 \mu \mathrm{g} / \mathrm{kg} / \mathrm{min}$ ) or abciximab (bolus $25 \mathrm{mg} / \mathrm{kg}$ and infusion $0.125 \mu \mathrm{g} / \mathrm{kg}$ ). All patients received aspirin, dose-adjusted heparin and, when possible, loading dose of clopidogrel of $300 \mathrm{mg} 2-6$ hours before the procedure. The primary end point, a composite of death, nonfatal MI and urgent targetvessel revascularization within 30 days after the index procedure, occurred more frequently in the tirofiban group than in the abciximab group ( $7.6 \%$ vs $6 \%, \mathrm{p}=0.03)$.

The superiority of abciximab was entirely driven by a higher rate of peri-procedural MI in the tirofiban arm, mortality rate and the need for target vessel revascularization completely overlapping between the two study arms. Interestingly, plotting the incidence of MI in the two study groups in the first 72 hours after randomization (Figure 1), it becomes clear that this had already started to diverge in the tirofiban arm 8 hours after randomization with respect to abciximab but after 24 hours the two curves were running parallel, which implies that the excess of MI in the tirofiban group occurred between 8 and 24 hours after randomization. Since the occurrence of MI in the trial was defined as the finding of levels of the MB isoform of creatine kinase that were at least 3 times the upper limit of the normal range in 2 separate blood samples, which were taken every 6 hours 


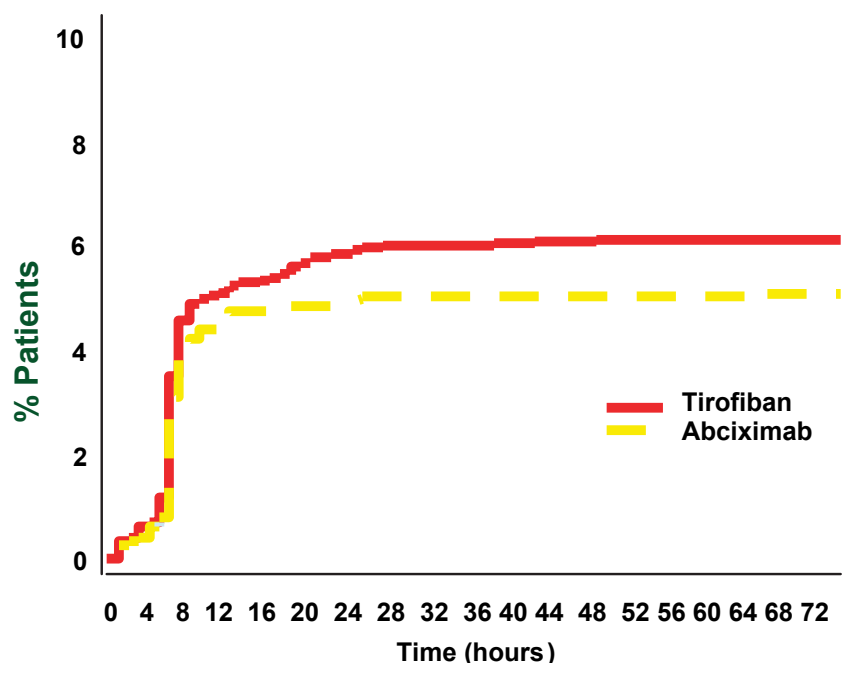

Figure I Incidence of myocardial infarction in the two study groups of TARGET trial (Topol et al 200I).

after the index procedure, these findings altogether strongly suggest that the excess of MI in the tirofiban arm was indeed generated directly during the procedure, a few minutes after the bolus of the two drugs were administered. However, starting from the first day after the procedure, the event rate in the two groups remained similar, thus diluting the small early excess of events in the tirofiban arm, which explains the finding of a similar overall event rate at 6 and 12 months. Several studies (Batchelor et al 2002; Ernst et al 2004) showed that, soon after the bolus, the degree of early platelet inhibition was higher after abciximab than after tirofiban (dosage used in the randomized efficacy study of tirofiban for outcomes and restenosis - RESTORE - (The RESTORE Investigators 1997) and TARGET studies (Topol et al 2001), thus offering more protection during PCI, where iatrogenic vessel injury is known to require almost complete platelet inhibition. As a consequence of the suboptimal platelet inhibition achieved soon after the RESTORE regimen (The RESTORE Investigators 1997), subsequent dose-ranging studies have led to an increase in the tirofiban bolus dose from 10 to $25 \mu \mathrm{g} / \mathrm{kg}$ (Schneider et al 2002). The new single high-dose bolus (SHDB) of tirofiban has been tested and compared to abciximab in several studies showing a similar level of platelet inhibition soon after the bolus administration (SHDB Tirofiban and Sirolimus Eluting Stent vs Abciximab and Bare Metal Stent in Acute Myocardial Infarction study - STRATEGY - (Valgimigli et al 2005; Campo et al 2006), Ernst et al (2004), Danzi et al (2004) and equivalent outcome at surrogate endpoints as ST-segment resolution in the STRATEGY trial (Valgimigli et al 2005; Campo et al
2006), or change in infarct-zone wall motion score index and global LV ejection fraction at 30 days in the study by Danzi et al (2004).

In the EVEREST trial (Bolognese et al 2005), NSTEACS patients were randomized to upstream vs in-catheterization-laboratory initiation of GPIIb/IIIa antagonists. The upstream arm received the standard dose of tirofiban, as used in the PRISM-PLUS trial (the PRISM-PLUS Investigators 1998) (the Platelet Receptor Inhibition in Ischemic Syndrome Management in Patients limited by Unstable Signs and Symptoms study). The in-catheterization laboratory arm received either abciximab or tirofiban with high dose bolus in a randomized fashion. The results, although preliminary, are intriguing. The patients in the upstream arm had better myocardial perfusion both on arrival in the catheterization laboratory and at the end of their procedure, as compared with the higher-dose tirofiban and abciximab patients, who had therapy initiated in the catheterization laboratory. It is plausible that upstream administration of GPIIb/IIIa inhibitors may not only prevent thrombus formation (and propagation) but may also lead to dissolution of platelet aggregates. Thus, the upstream use of the agent may lead to a lower thrombus load at the start of the procedure, hence less potential for distal embolization during the procedure.

\section{Abciximab vs eptifibatide}

There no are randomized clinical trials comparing abciximab with eptifibatide, but observational and/or pharmacological studies have been conducted and different information may be extrapolated.

In the COMPARE trial (Batchelor et al 2002) (the Comparison Of Measurements of Platelet Aggregation with Aggrastat, Reopro, and Eptifibatide study), 70 ACS patients undergoing PCI were randomized to receive abciximab, eptifibatide, or tirofiban at doses used in the EPISTENT (The EPISTENT Investigators 1998), PURSUIT (the PURSUIT Investigators 1998) (the Platelet Glycoprotein IIb/IIIa in Unstable Angina Receptor Suppression Using Integrilin Therapy study), and PRISM-PLUS/RESTORE trials, respectively. Platelet aggregation (PA) in response to $20 \mu \mathrm{mol} / \mathrm{L}$ of adenosine diphosphate was measured with turbidimetric aggregometry early (15 and 30 minutes) and late (4, 12, and 18-24 hours) after drug initiation. Although all regimens provided effective platelet inhibition, the tirofiban-RESTORE regimen produced less inhibition at 15-30 minutes compared with abciximab or eptifibatide. With continued infusion of the tirofiban-RESTORE regimen, platelet inhibition increased 
to levels comparable to those achieved by abciximab and eptifibatide. In contrast, although the abciximab regimen consistently inhibited PA early on, more recovery of PA occurred with continued infusion (4-12 hours). Of the four regimens evaluated, the eptifibatide regimen provided the most consistent platelet inhibition throughout infusion (Figure 2).

Schweiger et al (2003) reported the comparison of 2 sequential cohorts of consecutive patients undergoing PCI who received abciximab or eptifibatide. A total of 319 patients were treated with abciximab and 301 with eptifibatide. There were no differences in the incidence of major adverse cardiac events in hospital or at 30 days.

Raveendran et al (2007) reported the outcome of 576 patients underwent primary PCI and treated with GPIIb/IIIa receptor antagonists. Abciximab was given to 327 patients (57\%) and eptifibatide to 249 (43\%). Observed rates of inhospital death or MI did not differ between groups. This result persisted with adjustment for various patients.

Although these data are interesting, head to head randomized controlled trials would be desirable.

\section{Current guidelines}

Table 3 summarizes the indication for the use of abciximab according to current American and European guidelines. As reported, abciximab is currently recommended for the administration in the cath-lab immediately before coronary revascularization in patients with high risk NSTEACS.

Recently the ACUITY and the ACUITY-TIMING have been published (the Acute Catheterization and Urgent Intervention Triage Strategy study) trials (Stone et al 2006a, b. The first study used a $2 \times 2$ factorial design to compare a heparin with or without GPIIb/IIIa inhibition vs bivalirudin with or without upstream GPIIb/IIIa inhibition; a third arm tested bivalirudin alone with provisional use of GPIIb/IIIa inhibition. Authors found that bivalirudin + GPIIb/IIIa inhibitors compared with heparin + GPIIb/IIIa inhibitors was non-inferior on the composite of ischemia and major bleeding. As a contrary, bivalirudin alone vs heparin + GPIIb/IIIa inhibitors resulted in a non-inferior rate of composite ischemia and in a reduction of major bleeding. In the second study, two different strategies were compared: deferred selective use of GPIIb/IIIa inhibitors vs routine upstream administration of GPIIb/IIIa inhibitors. They found that a deferred selective use of GP2b/3a inhibitors resulted in a reduced rate of bleeding but a trend towards higher ischemic events. Regarding ACUITY (Stone et al 2006a) and ACUITY-TIMING (Stone et al 2006b) trials, two issues should be considered before their results may directly be applied to clinical practice: i) the median time between onset of medical therapy and catheterization was remarkably short ( $\sim 4$ hours), thus the results of ACUITY TIMING cannot be extrapolated to those scenarios where longer upstream infusion (24-48 hours) is carried out; ii) in the bivalirudin-alone group, the patients who did not receive clopidogrel before PCI showed a significantly worse ischemic outcome.

\section{Safety and tolerability}

The major concerns with use of GPIIb/IIIa receptor antagonists are the potential risk of major bleeding and thrombocytopenia.

\section{Bleeding}

Bleeding is generally increased in patients receiving GPIIb/IIIa compared to heparin alone, mainly because of excessively high heparin dose in the treated arm. Heparin dose reduction drastically decreases bleeding rates with no impact on ischemic endpoints. Thus, risk of bleeding can be reduced by the use of low-dose adjunctive heparin, early sheath removal, and meticulous post-procedure care of the vascular access site. The increase in bleeding complications related to use of abciximab might be due to its slowly reversible antiplatelet effects, which may be of concern in patients in whom an emergency coronary artery bypass graft is required. In such a scenario, platelet transfusion may be required to control bleeding.

\section{Thrombocytopenia}

In clinical trials of abciximab and in subsequent experience, it was found that about $1 \%$ of patients given this drug experienced acute, often severe thrombocytopenia (Aster 2005). After a second exposure to the drug, the rate for this complication rises to about 4\% (Aster 2005). In some instances, the onset of thrombocytopenia may be accompanied by fever, dyspnea, hypotension, and even frank anaphylaxis, occurring soon after starting the drug. Although most patients with abciximab-associated thrombocytopenia recover uneventfully, life-threatening bleeding has been described, including intracranial hemorrhage (Aster 2005). Although abciximab-induced thrombocytopenia usually occurs within a few hours of starting therapy with the drug, a subgroup of patients has been described in whom the drop in platelet levels occurred 5-8 days after the drug was administered (Aster 2005). Direct evidence for the immune destruction of platelets in patients who have received abciximab was provided by studies showing that a group of patients who developed severe thrombocytopenia after a second exposure 


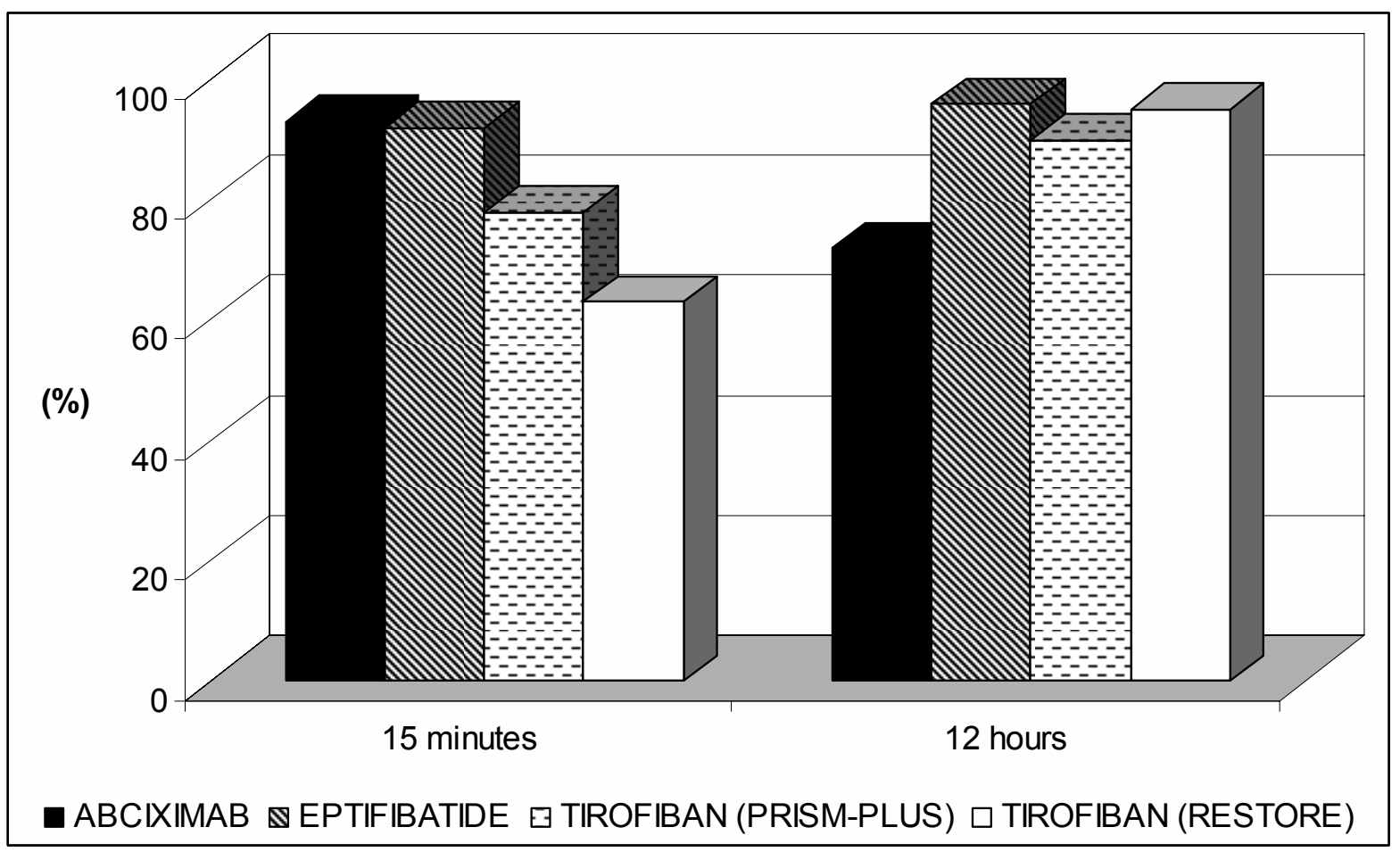

Figure 2 Percentage of patients in whom $>80 \%$ inhibition of 20 mol/LADP-induced platelet aggregation was achieved.At I5 minutes, inhibition was significantly higher in abciximab and eptifibatide groups as compared to tirofiban RESTORE group. At 12 hours, inhibition was significantly higher in eptifibatide and tirofiban RESTORE groups as compared to abciximab group. Adapted with permission from BatchelorWB, Tolleson TR, HuangY, et al 2002. Randomized comparison of platelet inhibition with abciximab, tirofiban and eptifibatide during percutaneous coronary intervention in acute coronary syndromes. The COMPARE Trial. Circulation, 106:1470. Copyright @ 2002 Lippincott Williams \& Wilkins.

to the drug all had strong IgG and/or IgM antibodies that reacted with abciximab-coated platelets in a flow cytometric assay. There are no published reports characterizing antibodies in patients who developed thrombocytopenia after a first exposure to abciximab, although unpublished observations suggest that antibodies similar to those found in patients given abciximab a second time are responsible for platelet destruction in most cases. These antibodies can

Table 3 Indication to use abciximab according to current guidelines

\begin{tabular}{|c|c|c|}
\hline Class & ACC/AHA guidelines & European task force report \\
\hline I & $\begin{array}{l}\text { - For NSTEACS patients in whom an initial invasive strategy is } \\
\text { selected.Abciximab is indicated only if there is no appreciable } \\
\text { delay to angiography and } \mathrm{PCl} \text { is likely to be performed. } \\
\text { - For high risk NSTEACS patients in whom } \mathrm{PCI} \text { has been selected } \\
\text { as a post-angiography management strategy, it is reasonable } \\
\text { administer abciximab if a GP Ilb/llla has not been started before } \\
\text { diagnostic angiography. }\end{array}$ & $\begin{array}{l}\text { - High risk NSTEACS patients not pretreated with GP Ilb/IIla } \\
\text { inhibitors and proceeding } \mathrm{PCl} \text {. }\end{array}$ \\
\hline II & $\begin{array}{l}\text { - It is reasonable to start treatment with abciximab as early as } \\
\text { possible before primary } \mathrm{PCI} \text { (with or without stenting) in patients } \\
\text { with STEMI. } \\
\text { - Abciximab administration in high risk NSTEACS patients in whom } \\
\text { bivalirudin was selected as anticoagulant. }\end{array}$ & $\begin{array}{l}\text { - Abciximab as ancillary therapy during primary } \mathrm{PCI} \text {. } \\
\text { - Stable CAD patients treated with } \mathrm{PCl} \text { of complex lesions, } \\
\text { threatening/actual vessel closure, visible thrombus, no/slow } \\
\text { reflow. } \\
\text { - When anatomy is known and } \mathrm{PCl} \text { planned to be performed } \\
\text { whitin } 24 \text { hours with GPIlb/llla inhibitors, most secure evidence } \\
\text { is for abciximab. }\end{array}$ \\
\hline III & $\begin{array}{l}\text { - Abciximab administration in ACS patients in whom } \mathrm{PCl} \text { is not } \\
\text { planned. }\end{array}$ & $\begin{array}{l}\text { - Abciximab is in fact unnecessary in patients treated with a non } \\
\text { invasive strategy. }\end{array}$ \\
\hline
\end{tabular}

Abbreviations: ACC,American College of Cardiology; ACS, acute coronary syndrome; AHA, American Heart Association; PCl, percutaneous coronary intervention; NSTEACS, non ST-segment elevation acute coronary syndrome; STEMI, ST-segment elvation myocardial infarction. 
be found in pretreatment blood samples, indicating that they are naturally occurring.

A platelet count should be performed routinely before and within 2-6 hours after starting treatment in any patient given abciximab to enable the early diagnosis of druginduced thrombocytopenia (Aster 2005). Some patients who develop thrombocytopenia are asymptomatic or exhibit only scattered petechial hemorrhages. Others experience bleeding from sites of catheterization, gastro-intestinal hemorrhage, or hematoma formation. Because the function of platelets remaining in the circulation is impaired by the inhibitor, all patients with this complication should be considered to be at risk for bleeding, and those with significant hemorrhage should be given platelet transfusions.

Patients who have received abciximab are at risk for a longer period of time because platelet function is impaired for up to 1 week, and thrombocytopenia sometimes persists for 3-5 days. On the basis of limited experience, it appears that patients who are sensitive to abciximab can safely receive tirofiban or eptifibatide at a later time. It is likely that the converse is true, but this has not yet been documented.

\section{Contraindications}

The contraindications to use of abciximab are generally similar to those of thrombolytic agents and are summarized in Table 4.

\section{Novel approaches to use abciximab Abciximab-coated stent}

Differently from other platelet GPIIb/IIIa receptor blockers, abciximab binds to MAC-1 (CD11b/18) on vascular endothelial cells and macrophages, thereby inhibiting inflammatory responses and smooth muscle cell proliferation after vascular injury. Furthermore, abciximab is known to bind to the vitronectin receptors found on platelets and vascular endothelial and smooth muscle cells and exert an inhibitory effect on migration and proliferation of smooth muscle cells after acute vessel injury. Thus, abciximab-coated stents have been created, on the hypothesis of their inhibitory effects in coronary restenosis and their prevention effect in subacute stent thrombosis. Previous studies (Hong et al 2004) demonstrated that abciximab-coated stents were safe and effective in the prevention of coronary restenosis in humans. Abciximab-coated stents have been tested also in 96 patients with acute MI (Kim et al 2006) treated with primary PCI and randomly allocated into 2 groups: group I received abciximab-coated stents, and group II received bare metal stents. One patient in group II had reinfarction and target lesion reintervention during hospital stay.
At coronary angiography follow-up late loss was significantly lower in group I than group II. In-stent restenosis rate was lower in group I than group II. During 1-year follow-up, 2 patients in group II (4.1\%) had MI, whereas no patients in group I suffered MI. Target lesion revascularization and total major adverse cardiac events rates were lower in group I than in group II (10.4\% vs $20.8 \%, \mathrm{p}=0.261$, and $10.4 \%$ vs $25.0 \%, \mathrm{p}=0.107$, respectively). It is important to note, in this study, the absence of episodes of acute MI by acute or subacute thrombotic occlusion during 1-year clinical follow-up in the patients who received abciximab-coated stents. The sample size of the study was small, but it is plausible to speculate that platelet aggregation was effectively inhibited with use of abciximab, and this effect could be maintained for a long-term period.

\section{Bolus-only use}

Traditionally, abciximab is administered as an intravenous bolus, followed by a prolonged infusion (12 hours). Many patients undergoing PCI (both in the United States and worldwide) do not receive a GPIIb/IIIa inhibitors, in part owing to concerns about bleeding and cost. In the present era of oral thienopyridines, where patients are preloaded with a high dose of clopidogrel (300-600 mg) in order to achieve an antiplatelet effect within 2-4 hours, the relevance of a prolonged abciximab infusion may be questionable, particularly given the widespread use of stents that have virtually eliminated the problem of abrupt closure. Moreover, the bolus of abciximab represents $\sim 75 \%$ of the total dose, and pharmacological data have shown that a single bolus $(0.25 \mathrm{mg} / \mathrm{kg})$ of abciximab induces $>80 \%$ of platelet aggregation inhibition and that this effect is prolonged for several hours. The prolonged abciximab infusion, as opposed to bolus-only administration, may contribute to increased bleeding complications and thrombocytopenia, without an incremental anti-ischemic benefit. The avoidance of prolonged infusion of abciximab has the potential to not only reduce vascular complications, but also to reduce the length of hospital stay and total cost of the procedure.

Marmur et al (2006) retrospectively analyzed consecutive patients $(n=1001)$ who underwent PCI and received an unfractionated heparin and bolus-only GPIIb/IIIa inhibitors regimen. All patients received clopidogrel and aspirin prior to PCI. Eptifibatide was used in the $58.3 \%$ of the cases, abciximab in the $37.3 \%$, and tirofiban in the $4.3 \%$. A bolusonly GPIIb/IIIa inhibitors strategy appears to maintain the anti-ischemic benefits, with the added benefit of reduced bleeding complications and the potential for reduced cost and shortened length of hospital stay. 
Table 4 Contraindications to abciximab use

\begin{tabular}{l} 
Absolute contraindications \\
Intracranial aneurysm \\
Artery-venous malformation \\
Active major bleeding \\
Coagulopathy (eg, hemophilia) \\
Intracranial mass \\
Stroke in the previous 30 days \\
Hemorrhagic stroke \\
Surgery or trauma in the preceding 6 weeks \\
Thrombocytopenia \\
Concurrent dextran therapy \\
Murine protein hypersensitivity \\
Vasculitis \\
Relative contraindications \\
Concurrent anticoagulation therapy (eg, with warfarin) \\
Breast feeding \\
Pregnancy \\
Uncontrolled hypertension (SBP $>200$ mmHg, DBP $>110 \mathrm{mmHg}$ ) \\
Thrombolytic therapy \\
Abciximab hypersensitivity \\
\hline Abrevations: DBP,
\end{tabular}

Abbrevations: DBP, diastolic blood pressure; SBP, systolic blood pressure.

In the EASY trial (Bertrand et al 2006) (the Early Discharge after Transradial Stenting of Coronary Arteries study), 1005 patients were randomized after a bolus of abciximab and uncomplicated transradial percutaneous coronary stent implantation either to same-day home discharge and no infusion of abciximab or to overnight hospitalization and a standard 12-hour infusion of abciximab. The primary composite end point of the study was the 30-day incidence of any of the following events: death, MI, urgent revascularization, major bleeding, repeat hospitalization, access site complications, and severe thrombocytopenia. They found that same-day home discharge after uncomplicated transradial coronary stenting and bolus only of abciximab is not clinically inferior, in a wide spectrum of patients, to the standard overnight hospitalization and a bolus followed by a 12 -hour infusion.

In the EPIC trial, 2099 patients scheduled to high-risk PCI were enrolled and randomized to 3 treatment arms: bolus and 12-hour infusion of placebo, abciximab bolus of $0.25 \mathrm{mg} / \mathrm{kg}$ plus 12-hour placebo infusion, and abciximab bolus plus 12 -hour infusion $(10 \mu \mathrm{g} / \mathrm{min})$. It is important to note that thienopyridines were not administered to patients in the EPIC as protocol mandated balloon angioplasty only. Accordingly, stent was used in the EPIC only to treat imminent or complete abrupt closure of the vessel undergoing angioplasty. The primary end point of the EPIC trial was a composite of death, MI, or urgent intervention during the first 30 days after randomization. Recently, an analysis of the EPIC outcomes at 6-hour intervals during the first 24 hours after PCI to identify any early benefit derived from the abciximab bolus-only arm has been published (Marmur et al 2006). This analysis demonstrates a significant reduction in the composite end point of death, MI, or urgent intervention at 6 hours in the abciximab bolus-only group compared with the placebo group. After 6 hours and throughout the first 24 hours post-procedure, a numerical reduction was apparent, but statistical significance was not achieved. The fact that a bolus-only strategy appears to be effective in the first 6 hours may be relevant in the context of stenting and routine administration of a loading dose of clopidogrel.

\section{Intracoronary use}

All clinical trials studied solely the intravenous administration of abciximab and there is only limited information on the efficacy of intracoronary administration of abciximab. In patients with ACS, intracoronary administration of abciximab with very high local concentrations of the antibody may be favorable in dissolution of thrombi and microemboli with subsequent better and faster recovery of myocardial microcirculation and reduction of major adverse cardiac events (MACE). Wöhrle et al (2003) reported a series of 403 consecutive patients with unstable angina or acute MI undergoing emergency coronary intervention retrospectively stratified according to the method of application of abciximab (20 $\mathrm{mg}$ bolus of abciximab was given intravenously in 109 patients and intracoronarily in 294 patients, followed by 12 hours of intravenous infusion of $10 \mathrm{mg}$ in both groups). At 30 days, the incidence of MACE (death, MI, urgent revascularization) was significantly lower in the patients with intracoronary compared with intravenous administration of abciximab (10.2\% vs $20.2 \%$; $=0.008)$, which was independent from stenting in multivariate analysis. The effect was most pronounced in patients with pre-procedural TIMI 0/1 flow (MACE: intracoronary $11.8 \%$ vs intravenous $27.5 \%, \mathrm{p}=0.002)$.

Burzotta et al (2003), with their angiographic data in a limited subset of patients, extended the findings of Wöhrle, suggesting that in patients with ACS, the reduction of angiographically evident thrombus obtained with intracoronary administration of abciximab translates into an acute improvement of coronary blood flow.

\section{Conclusions}

Several randomized trials have reported the ability of abciximab to reduce death or MI when used as adjunctive therapy to PCI. Accordingly, abciximab is recommended 
by the American College of Cardiology/American Heart Association and European Society of Cardiology guidelines (Braunwald et al 2002; Stone et al 2006a; Task force for percutaneous coronary intervention of the European Society of Cardiology 2005; Task force for diagnosis and treatment of non ST-segment elavation acute coronary syndromes 2007; ACC/AHA 2007). There is increasing evidence that treatment with clopidogrel prior to PCI prevents postprocedural ischemic complications. Several studies have shown that a 600-mg loading dose of clopidogrel, compared with the usual 300-mg dose, is as safe and is significantly more rapidly acting. However, it is known that the antiplatelet effect provided by $600 \mathrm{mg}$ of clopidogrel is not sufficient for patients with STEMI or moderate-high risk ACS undergoing PCI (Kastrati et al 2006). Thus, GPIIb/IIIa inhibitors show a critical role in the current management of high risk patients. It is plausible that in the future the abciximab bolus-only scheme for facilitating PCI may become a more widespread choice to maintain efficacy while minimizing safety and costs. Randomized controlled trials are currently underway.

Current data suggest that there are no differences between the three GPIIb/IIIa inhibitors approved for clinical use in terms of degree of platelet inhibition, particularly after the revision of the tirofiban bolus dose. Nevertheless, abciximab still today remains the GPIIb/IIIa inhibitor with greater evidence of benefit from randomized clinical trials showing a significant and consistent reduction of death and reinfarction in high risk patients undergoing PCI.

\section{References}

ACC/AHA. 2007. ACC/AHA 2007. Guidelines for the management of patients with unstable angina/non-ST-elevation myocardial infarction. J Am Coll Cardiol, 50:e1.

Antoniucci D, Rodriguez A, Hempel A, et al. 2003. A randomized trial comparing primary infarct artery stenting with or without abciximab in acute myocardial infarction. J Am Coll Cardiol, 42:1879.

Aster RH. 2005. Immune thrombocytopenia caused by glycoprotein IIb/IIIa inhibitors. Chest, 127:53S.

Atwater BD, Roe MT, Mahaffey KW. 2005. Platelet glycoprotein IIb/IIIa receptor antagonists in non-ST segment elevation acute coronary syndromes. A review and guide to patient selection. Drugs, 65:313.

Batchelor WB, Tolleson TR, Huang Y, et al. 2002. Randomized comparison of platelet inhibition with abciximab, tirofiban and eptifibatide during percutaneous coronary intervention in acute coronary syndromes. The COMPARE Trial. Circulation, 106:1470.

Bertrand OF, De Larochellière R, Rodés-Cabau J, et al. 2006. A randomized study comparing same-day home discharge and abciximab bolus only to overnight hospitalization and abciximab bolus and infusion after transradial coronary stent implantation. Circulation, 114:2636.

Bolognese L, Falsini G, Liistro F, et al. 2005. Randomized comparison of upstream tirofiban versus downstream high bolus dose tirofiban or abciximab on tissue-level perfusion and troponin release in high-risk acute coronary syndromes treated with percutaneous coronary interventions: the EVEREST trial. J Am Coll Cardiol, 47:522.
Braunwald E, Antman EM, Beasley JW, et al. 2002. ACC/AHA 2002 guideline update for the management of patients with unstable angina and non-ST-segment elevation myocardial infarction - summary article: a report of the American College of Cardiology/American Heart Association task force on practice guidelines (Committee on the Management of Patients With Unstable Angina). J Am Coll Cardiol, 40:1366.

Burzotta F, Romagnoli E, Trani C, et al. 2003. Intracoronary administration of abciximab acutely increases flow through culprit vessels of patients with acute coronary syndromes undergoing percutaneous coronary intervention. Circulation, 108:e138.

Campo G, Valgimigli M, Gemmati D, et al. 2006. Value of platelet reactivity in predicting response to treatment and clinical outcome in patients undergoing primary coronary intervention: insights into the STRATEGY study. J Am Coll Cardiol, 48:2178.

Danzi GB, Sesana M, Capuano C, et al. 2004. Comparison in patients having primary coronary angioplasty of abciximab versus tirofiban on recovery of left ventricular function. Am J Cardiol, 94:35.

De Luca G, Suryapranata H, Stone GW, et al. 2006. Relationship between patient's risk profile and benefits in mortality from adjunctive abciximab to mechanical revascularization for ST-segment elevation myocardial infarction: A meta-regression analysis of randomized trials. J Am Coll Cardiol, 47:685.

Ernst N, Suryapranata H, Miedema K, et al. 2004. Achieved platelet aggregation inhibition after different antiplatelet regimens during percutaneous coronary intervention for ST-segment elevation myocardial infarction. $J$ Am Coll Cardiol, 44:1187.

Gowda RM, Khan IA, Vasavada BC, et al. 2004. Therapeutics of Platelet Glycoprotein IIb/IIIa Receptor Antagonism. Am J Therapeutics, 11:302.

Hong YJ, Jeong MH, Kim W, et al. 2004. Effect of abciximab-coated stent on in-stent intimal hyperplasia in human coronary arteries. Am J Cardiol, 94:1050.

Kabbani SS, Watkins MW, Ashikaga T, et al. 2001. Platelet reactivity characterized prospectively. A determinant of outcome 90 days after percutaneous coronary intervention. Circulation, 104:181.

Kabbani SS, Watkins MW, Ashikaga T, et al. 2003. Usefulness of platelet reactivity before percutaneous coronary intervention in determining cardiac risk one year later. Am J Cardiol, 91:876.

Kastrati A, Mehilli J, Neumann FJ, et al. 2006. Abciximab in patients with acute coronary syndromes undergoing percutaneous coronary intervention after clopidogrel pretreatment. The ISAR-REACT 2 Randomized Trial. JAMA, 295:E1.

Kastrati A, Mehilli J, Schuhlen H, et al. 2004. A clinical trial of abciximab in elective percutaneous coronary intervention after pretreatment with clopidogrel. N Engl J Med, 350:232.

Kim W, Jeong MH, Kim KH, et al. 2006. The clinical results of a platelet glycoprotein IIb/IIIa receptor blocker (abciximab: ReoPro)-coated stent in acute myocardial infarction. J Am Coll Cardiol, 47:933.

Mager DE, Mascelli MA, Kleiman NS, et al. 2003. Simultaneous modeling of abciximab plasma concentrations and ex vivo pharmacodynamics in patients undergoing coronary angioplasty. J Pharma Exp Ther, 307:969.

Marmur JD, Mitre CA, Barnathan E, et al. 2006. Benefit of bolus-only platelet glycoprotein IIb/IIIa inhibition during percutaneous coronary intervention: insights from the very early outcomes in the Evaluation of 7E3 for the Prevention of Ischemic Complications (EPIC) trial. Am Heart J, 152:876.

Marmur JD, Poludasu S, Agarwal A, et al. 2006. Bolus-only platelet glycoprotein IIb-IIIa inhibition during percutaneous coronary intervention. J Invasive Cardiol, 18:521.

Matetzky S, Shenkman B, Guetta V, et al. 2004. Clopidogrel resistance is associated with increased risk of recurrent atherothrombotic events in patients with acute myocardial infarction. Circulation, 109:3171.

Montalescot G, Antoniucci D, Kastrati A, et al. 2007. Abciximab in primary coronary stenting of ST-elevation myocardial infarction: a European meta-analysis on individual patients data with long-term follow-up. Eur Heart J, 28:443. 
Montalescot G, Barragan P, Wittenberg O, et al. 2001. Platelet glycoprotein $\mathrm{IIb} / \mathrm{III}$ inhibition with coronary stenting for acute myocardial infarction. N Engl J Med, 344:1895.

Neumann FJ, Kastrati A, Schmitt C, et al. 2000. Effect of glycoprotein $\mathrm{IIb} / \mathrm{III}$ receptor blockade with abciximab on clinical and angiographic restenosis rate after the placement of coronary stents following acute myocardial infarction. J Am Coll Cardiol, 35:915.

Raveendran G, Ting HH, Best PJ, et al. 2007. Eptifibatide vs. abciximab as adjunctive therapy during primary percutaneous coronary intervention for acute myocardial infarction. Mayo Clin Proc, 82:196.

Schneider DJ, Herrmann HC, Lakkis N, et al. 2002. Enhanced early inhibition of platelet aggregation with an increased bolus of tirofiban. Am J Cardiol, 90:1421.

Schror K, Weber AA. 2003. Comparative Pharmacology of GP IIb/IIIa Antagonists. $J$ Thromb Thrombolysis, 15:71.

Schweiger MJ, Changezi HU, Naglieri-Prescod D, et al. 2003. Open-label, sequential comparison of eptifibatide with abciximab for patients undergoing percutaneous coronary intervention. Clin Ther, 25:225.

Silva MA, Gandhi PJ. 2004. Selection of glycoprotein IIb/IIIa inhibitors for upstream use in patients with diabetes experiencing unstable angina or non-ST segment elevation myocardial infarction. What have we learned in the last 10 years? J Clin PharmTher, 29:497.

Stone GW, McLaurin BT, Cox DA, et al. 2006. Bivalirudin for patients with acute coronary syndromes. $N$ Engl J Med, 355:2203.

Stone GW, Bertrand ME, Moses JW, et al. 2006. Routine upstream initiation vs. deferred selective use of glycoprotein IIb/IIIa inhibitors in acute coronary syndromes. the ACUITY-TIMING trial. J Am Med Ass, 297:591.

The CAPTURE Investigators. 1997. Randomized placebo-controlled trial of abciximab before and during coronary intervention in refractory unstable angina: the CAPTURE study. Lancet, 349:1429.

The EPIC Investigators. 1994. Use of monoclonal antibody directed against the platelet glycoprotein IIb/IIIa receptor in high-risk coronary angioplasty. $N$ Engl J Med, 330:956.

The EPILOG Investigators. 1997. Platelet glycoprotein IIb/IIIa receptor blockade and low-dose heparin during percutaneous coronary revascularization. N Engl J Med, 336:1689.

The EPISTENT Investigators. 1998. Randomised placebo-controlled and balloon-angioplasty controlled trial to assess safety of coronary stenting with use of platelet glycoprotein-IIb/IIIa blockade. Lancet, 352:87.
The GUSTO IV-ACS Investigators. 2001. Effect of glycoprotein IIb/IIIa receptor blocker abciximab on outcome in patients with acute coronary syndromes without early coronary revascularisation: the GUSTO IVACS randomised trial. Lancet, 357:1915.

The PRISM PLUS Investigators. 1998. Inhibition of the platelet glycoprotein $\mathrm{IIb} / \mathrm{III}$ receptor with tirofiban in unstable angina and non-Q-wave myocardial infarction. $N$ Engl J Med, 338:1488.

The PURSUIT Trial Investigators. 1998. Inhibition of platelet glycoprotein $\mathrm{IIb} / \mathrm{III}$ with eptifibatide in patients with acute coronary syndromes. N Engl J Med, 339:436,

The RESTORE Investigators. 1997. Effects of platelet glycoprotein IIb/IIIa blockade with tirofiban on adverse cardiac events in patients with unstable angina or acute myocardial infarction undergoing coronary angioplasty. Circulation, 96:1445.

Task force for percutaneous coronary intervention of the european society of cardiology. 2005. Guidelines for percutaneous coronary intervention. Eur Heart J, 26:804.

Task force for diagnosis and treatment of non ST-segment elavation acute coronary syndromes. 2007. Guidelines for the diagnosis and treatment of non ST-segment elavation acute coronary syndromes. Eur Heart $J, 28: 1598$.

Topol E, Moliterno D, Herrmann H, et al. 2001. Comparison of two platelet glycoprotein IIb/IIIa inhibitors, tirofiban and abcix imab, for the prevention of ischemic events with percutaneous coronary revascularization. N Engl J Med, 344:1888.

Topol EJ, Byzova TV, Plow EF. 1999. Platelet GPIIb-IIIa blockers. Lancet, 353:227.

Valgimigli M, Percoco G, Malagutti P, et al. 2005. Tirofiban and sirolimuseluting stent vs. abciximab and bare-metal stent for acute myocardial infarction: a randomized trial. JAMA, 293:2109.

Wöhrle J, Grebe OC, Nusser T, et al. 2003. Reduction of major adverse cardiac events with intracoronary compared with intravenous bolus application of abciximab in patients with acute myocardial infarction or unstable angina undergoing coronary angioplasty. Circulation, 107:1840. 
